\title{
Estimation of under-5 child mortality rates in 52 low-migration countries
}

\author{
Nirmal Sapkota ${ }^{1}$, Nirmal Gautam ${ }^{1}$, Apiradee Lim $^{2}$, Attachai Ueranantasun $^{3}$ \\ ${ }^{1}$ Lecturer, Department of Medical and Allied Science, Faculty of Public Health, Karnali College of Health Science, Gaushala, Kathmandu, Nepal; ${ }^{2}$ Associate \\ Professor, Department of Mathematics and Computer Science, Faculty of Science and Technology, Prince of Songkla University, Pattani; ${ }^{3}$ Assistant Professor, \\ Department of Mathematics and Computer Science, Faculty of Science and Technology, Prince of Songkla University, Pattani, Thailand.
}

Reduction of the under-5 mortality rate is a target of the Sustainable Development Goals. Therefore, this study aimed to estimate under-5 child mortality rates in 52 low-migration countries using population data. The study utilized population data from the US Census Bureau from 1990 to 2015. The method involved first estimating mortality rates for countries with negligible net migration and then applying these rates to countries with matching mortality profiles, where it is reasonable to assume that migration is negligible for children under the age of 5 years. The highest child mortality was concentrated in the African region, followed by Asia and the Western region. However, steady progress in child mortality trends was concentrated in low-income countries. This simple method demonstrated that child mortality has significantly improved in high-income countries, followed by middle- and low-income countries. To reduce the under- 5 mortality rates even further in these 52 countries, there is a need to accelerate equitable plans and policies related to child health to promote children's longevity and survival.

Key words: Child; Child health; Mortality; International migration

\section{Corresponding author Nirmal Gautam \\ https://orcid.org/0000-0002-1375-3998}

Department of Medical and Allied Science, Faculty of Public Health, Karnali College of Health Science, Gaushala, Kathmandu 44602, Nepal

TEL +977-9851187256 FAX +977-01-4486464

E-MAIL gnirmal655@gmail.com

Received Jun 7, 2020 Revised Jul 13, 2020 Accepted Jul 28, 2020 (a) This is an Open Access article distributed under the terms of the Creative Commons Attribution NonCommercial License (http://creativecommons.org/licenses/by-nc/4.0/) which permits unrestricted noncommercial use, distribution, and reproduction in any medium, provided the original work is properly cited.

\section{INTRODUCTION}

The ability of a nation to expand in the future is deeply dependent on its current quality of child care [1]. The quality of caregiving and structural measures has implications for children's social, cognitive, and language development [2], but these factors are strongly affected by poverty [3]. About half of the world's children have experienced extreme poverty, and most children have encountered various dimensions of poverty during their life [4]. Children from low-income and some middle-income countries experience deficient health care facilities, education, and other fundamental services in comparison with those of high-income countries. This can lead to the burdens of stunting and malnutrition, as well as higher rates of other morbidities and mortality [5].

Throughout the world, the physiological patterns of morbidity and mortality are consistent, but differences across countries in health systems and socioeconomic conditions can shape individuals' health [5]. Consequently, a poor supply of medical technologies, low coverage of health services, malnutrition, overcrowding, indoor air pollution, poor hygiene and sanitation, and geographical variation lead to discrepancies in health and life expectancy [6]. For instance, children who have a healthy lifestyle will be more likely to be healthy and to engage in healthy behaviors [7], which can pre- 
vent illness, promote health, and prolong the life of people, including children [6]. Thus, children from developed countries have access to advanced health systems and modern medical technologies, which promote their health and longevity [4]. Nevertheless, in developing countries, the majority of children are distant from modern health care systems and their fundamental health rights are not guaranteed [8]. Therefore, children in these circumstances are more vulnerable to morbidity, disability, and mortality due to a lack of basic fundamental health services [5]. Additionally, children from developing countries have a 16 times lower likelihood of reaching their fifth birthday as compared to children from developed countries [8]. In developing countries, 12.7 million children died in 1990, a number that decreased to 4.8 million in 2015. In sharp contrast, however, only 1.1 million child deaths occurred in developed countries $[4,9,10]$. These huge differences in child mortality between developed and developing countries are essentially due to persistent disparities in health equity and health care facilities $[4,10]$.

Numerous studies have been conducted across the globe in order to identify demographic and regional trends and patterns of child mortality using different statistical tools and techniques [11,12]. The reliability of these techniques is improved if countries have complete vital registration and demographic data [13]. However, most developing and even developed countries do not have accurate and reliable demographic data due to poor functioning of the vital registration and demographic surveillance system $[12,14]$. Thus, there may be differences between estimated trends and patterns of childhood mortality and the actual trends, and it may be difficult to make accurate estimations [12,13]. Although it is challenging to collect reliable and complete census and demographic data for many countries [12,14], the US Census Bureau provides accurate and valid population data for more than 192 countries [15]. These stable population data provide better insights into estimations of trends and patterns in mortality rate of children, and even for the adult population if migration from a given country is negligible [16]. In this regard, estimating child mortality from population data would be beneficial for countries lacking complete records of births, deaths, and other vital data, which impedes an understanding of mortality in under-5 children and its patterns and trends. Furthermore, this estimation of child mortality also plays a crucial role in preventing and controlling child mortality, particularly in developing countries, is highly important for achieving the targets set by the Sustainable Development Goals (SDGs) [4]. Therefore, the findings of this study can contribute to the effectiveness of programs for controlling the mortality rates in specific countries and motivate policy-makers and program implementers to shift the focus of programs from raising general awareness to provide other essential information. Additionally, it will help to develop flexible strategies to meet future needs for constructing healthcare facilities and services to deliver improvements in health among the vulnerable population of both developed and developing countries. Therefore, this study aimed to estimate under- 5 child mortality in 52 low-migration countries using large-scale population data from the US Census Bureau.

\section{METHODS}

This study utilized population data from the US Census Bureau from 1990 to 2015 [15]. In total, 52 low-migration countries were selected for this study, with 21 in Africa, 19 in Asia, and 12 in the West. These regions were grouped according to geographical boundaries and the pattern of mortality rates for each country. It has been well documented that most African countries share similar patterns of birth rates and death rates, while Asian and Western countries have different patterns [8]. Moreover, countries from each region (Africa, Asia, and the West) have similar patterns of fertility and mortality rate [16]. Therefore, this study aimed to estimate the mortality rates of under-5 children from the population data using a simple method based on the stable population data of children. Specifically, to estimate the age-specific mortality rates of under- 5 children, we applied:

$$
\text { Mortality rate }=1-\frac{N(x+1, t+1)}{N(x, t)}
$$

In this equation, $N(x, t)$ is the number of children aged $x$ in year $t$ and $N(x+1, t+1)$ is the number of children aged $x+1$ in year $t+1$.

The method first estimated the mortality rate based on the assumption of a low migration rate for each country, which was estimated by minimizing the values for all years (1990 to 2015). It was found that the data from 1990 to 2015 gave results that needed smoothing, and better results were obtained by selecting a few years. Thus, in this study, we only selected data from 1991, 1992, 1995, 1996, 2000, 2001, 2005, 2006, and 2008-2015, and a cubic root scale was applied to obtain better results. Consequently, single-year age groups from 1 to 5 years were used and the mortality rates of the 52 countries were calculated based on assumption of low migration. The selected countries, for which it was assumed that the net migration rate per 100,000 population was low in 2010-2015, are shown in Table 1 [17]. Additionally, children were grouped by age at 1 -year intervals from 1 to 5 years, and the mortality rate per 100,000 live births was estimated. The US Census Bureau granted us permission to use their data, which are freely available from the US Census Bureau website [15]. 
Table 1. Net Migration Rate for 52 Countries $(N=52)$

\begin{tabular}{|c|c|c|c|c|c|c|}
\hline \multirow{2}{*}{ Countries } & \multicolumn{6}{|c|}{ Net migration rate per 1,000} \\
\hline & 1990-1995 & $1995-2000$ & $2000-2005$ & $2005-2010$ & 2010-2015 & Average \\
\hline Nigeria & -0.2 & -0.2 & -0.3 & -0.4 & -0.4 & -0.3 \\
\hline Sudan & 5.9 & -4.9 & -3.8 & -6.6 & -3.2 & -2.5 \\
\hline Congo & 1.7 & 3.3 & 2.9 & 4.7 & -2.6 & 2.0 \\
\hline Tanzania & 4.3 & -1.3 & -1.6 & -1.2 & -0.8 & -0.1 \\
\hline Angola & 2.2 & -1.7 & 1.9 & 0.8 & 0.7 & 0.8 \\
\hline Cameroon & -0.8 & -0.7 & -0.7 & -0.6 & -0.3 & -0.6 \\
\hline Vietnam & -1.1 & -0.6 & -1.6 & -2.0 & -0.4 & -1.1 \\
\hline China & -0.1 & -0.1 & -0.3 & -0.4 & -0.3 & -0.2 \\
\hline India & -0.1 & -0.1 & -0.4 & -0.5 & -0.4 & -0.3 \\
\hline Philippines & -1.5 & -2.1 & -2.7 & -3.3 & -1.3 & -2.2 \\
\hline Sri Lanka & -2.9 & -5 & -4.7 & -5.2 & -4.7 & -4.5 \\
\hline Myanmar & -3.3 & -2.4 & -5.3 & -6.0 & -1.9 & -3.8 \\
\hline Brazil & 0.0 & 0.0 & 0.0 & 0.0 & 0.0 & 0.0 \\
\hline Mexico & -2.9 & -4.8 & -5.5 & -0.4 & -0.5 & -2.8 \\
\hline Venezuela & 0.0 & 0.0 & -0.1 & -0.2 & -0.5 & -0.2 \\
\hline Uganda & 1.3 & -0.4 & 0.0 & -0.9 & -0.8 & -0.2 \\
\hline Burkina Faso & -3.2 & -2.5 & -2.0 & -1.7 & -1.5 & -2.2 \\
\hline Nepal & 0.8 & -4.1 & -6.5 & -7.8 & -2.7 & -4.1 \\
\hline Ghana & -0.2 & -1.3 & 1.6 & 1.6 & -0.4 & 0.3 \\
\hline Iran & -7.2 & 1.9 & -0.2 & -1.5 & -1.0 & -1.6 \\
\hline Uzbekistan & -3.0 & -2.0 & -1.9 & -1.0 & -0.5 & -1.7 \\
\hline Indonesia & -0.4 & -0.3 & -0.8 & -0.6 & -0.7 & -0.6 \\
\hline North Korea & 0.0 & -0.1 & -0.2 & -0.2 & -0.2 & -0.1 \\
\hline Thailand & -2.1 & 2.3 & 1.2 & 0.2 & 0.5 & 0.4 \\
\hline Madagascar & 0.2 & -0.1 & -0.1 & -0.1 & -0.1 & -0.1 \\
\hline Mozambique & 9.0 & -0.6 & 0.3 & -0.4 & -0.2 & 1.6 \\
\hline Morocco & -3.6 & -4.0 & -4.4 & -3.6 & -1.8 & -3.5 \\
\hline Bangladesh & -1.4 & -1.2 & -2.2 & -4.8 & -3.2 & -2.6 \\
\hline Malaysia & 3.1 & 4.5 & 5.3 & 5.3 & 5.3 & 4.7 \\
\hline Ivory Coast & 5.7 & 2.3 & -3.4 & -2.1 & -0.7 & 0.4 \\
\hline Japan & 0.1 & -0.2 & 0.3 & 0.4 & 0.6 & 0.2 \\
\hline Argentina & 0.2 & -0.4 & -0.5 & -0.4 & 0.1 & -0.2 \\
\hline Albania & -27.8 & -11.5 & -11.4 & -14.4 & -6.4 & -14.3 \\
\hline Armenia & -29.4 & -14.2 & -10.6 & -12.5 & -2.1 & -13.8 \\
\hline Mongolia & -7.9 & -4.5 & -1.2 & -1.1 & -1.1 & -3.2 \\
\hline Colombia & -1.8 & -1.5 & -1.3 & -1.0 & 0.3 & -1.1 \\
\hline Malawi & -17.9 & -1.1 & -1.0 & -0.9 & -1.0 & -4.4 \\
\hline Zambia & -3.5 & 0.4 & -2.7 & -2.7 & -0.7 & -1.8 \\
\hline Central African Republic & 3.3 & 1.7 & -1.3 & -6.0 & -17.8 & -4.0 \\
\hline Benin & 2.5 & -0.1 & 0.7 & -1.1 & -0.9 & 0.2 \\
\hline Mali & -3.8 & -2.8 & -1.1 & -1.4 & -3.7 & -2.6 \\
\hline Mauritania & -4.1 & -3.6 & -0.7 & 0.6 & 1.3 & -1.3 \\
\hline Niger & -0.1 & -0.2 & -0.2 & -0.3 & 0.2 & -0.1 \\
\hline Bhutan & -22.0 & 0.1 & 2.0 & -3.3 & 0.1 & -4.6 \\
\hline Paraguay & -1.4 & -1.7 & -1.7 & -3.9 & -2.7 & -2.3 \\
\hline Peru & -3.1 & -2.0 & -6.7 & -8.5 & -4.2 & -4.9 \\
\hline Uruguay & -1.3 & -1.6 & -6.3 & -3.0 & -1.8 & -2.8 \\
\hline Fiji & -9.0 & -9.8 & -14.4 & -5.6 & -12.0 & -10.2 \\
\hline Papua New Guinea & -0.9 & -0.9 & -2.7 & 1.1 & -0.1 & -0.7 \\
\hline Honduras & -2.9 & -2.1 & -1.2 & -0.6 & -0.7 & -1.5 \\
\hline Somalia & -22.3 & 0.0 & 0.0 & -3.6 & -3.6 & -5.9 \\
\hline Bulgaria & -5.8 & -6.3 & -2.8 & -2.2 & -2.0 & -3.8 \\
\hline
\end{tabular}




\section{RESULTS}

After estimating the under-5 child mortality rate for 52 low-migration countries in this study, we categorized the countries into three groups, as shown in the tables. These groups were formed based on geographical location (African, Asian, and Western countries). In total, data from 52 low-migration countries were analyzed in this study during the period 1990-2015. Table 2 shows the estimated child mortality rate per 100,000 live births for 21 African countries (Angola, Benin, Burkina Faso, Cameroon, Central African Republic, Congo, Ghana, Ivory Coast, Madagascar, Malawi, Mali, Mauritania, Morocco, Mozambique, Niger, Nigeria, Somalia, Sudan, Tanzania, Uganda, and Zambia). It was found that Somalia had the highest child mortality rate (225 per 100,000 live births) in 1990, followed by Malawi (163 per 100,000 live births) and Mali (163 per 100,000 live births), while Mauritania (99 per 100,0000 live births) had the lowest child mortality. Subsequently, in 2015, Somalia also showed the highest child mortality rate (61 per 100,000 live births), while Morocco was estimated to have the lowest (38 per 100,000 live births).

Table 3 shows the estimated child mortality rates for 19 Asian countries. In Table 3, of the Asian countries (Armenia, Bangladesh, Bhutan, China, India, Indonesia, Iran, Japan, Malaysia, Mongolia, Myanmar, Nepal, North Korea, Papua New Guinea, Philippines, Sri Lanka, Thailand, Uzbekistan, and Vietnam), Uzbekistan had the highest child mortality rate (118 per 100,000 live births), followed by Myanmar (116 per 100,000 live births), in 1990, while Japan had the lowest child mortality rate (39 per 100,000 live births). In 2015, Armenia had the highest child mortality rate (45 per 100,000 live births), while Japan had the lowest child mortality rate (12 per 100,000 live births).

Similarly to the process illustrated above, Table 4 presents findings for 12 Western countries (Albania, Argentina, Brazil, Bulgaria, Columbia, Fiji, Honduras, Mexico, Paraguay, Peru, Uruguay, and Venezuela). Of these countries, Albania had the highest child mortality rate (128 per 100,000 live births) in 1990, while Argentina had the lowest estimated child mortality rate (44 per 100,000 live births). In 2015, Fiji had the highest child mortality rate (50 per 100,000 live births), whereas Argentina had the lowest child mortality rate (18 per 100,000 live births).

\section{DISCUSSION}

This study estimated under- 5 child mortality rates in 52 low-migration countries by analyzing child population data from 1990 to 2015. A simple method was applied to estimate child mortality. Under-5 mortality is typically understood as
Table 2. Under-5 Mortality Rate per 100,000 Live Births for 21 African Countries $(N=21)$

\begin{tabular}{|c|c|c|}
\hline Country & $\begin{array}{c}\text { Death rate/ } \\
100,000 \text { live } \\
\text { births in } 1990\end{array}$ & $\begin{array}{c}\text { Death rate/ } \\
100,000 \text { live } \\
\text { births in } 2015\end{array}$ \\
\hline Angola & 152 & 55 \\
\hline Benin & 131 & 47 \\
\hline Burkina Faso & 144 & 59 \\
\hline Cameroon & 126 & 53 \\
\hline Central African Republic & 161 & 56 \\
\hline Congo & 122 & 53 \\
\hline Ghana & 124 & 45 \\
\hline Ivory Coast & 113 & 46 \\
\hline Madagascar & 128 & 41 \\
\hline Malawi & 163 & 44 \\
\hline Mali & 163 & 55 \\
\hline Mauritania & 99 & 44 \\
\hline Morocco & 108 & 38 \\
\hline Mozambique & 149 & 47 \\
\hline Niger & 158 & 59 \\
\hline Nigeria & 148 & 60 \\
\hline Somalia & 225 & 61 \\
\hline Sudan & 116 & 55 \\
\hline Tanzania & 117 & 43 \\
\hline Uganda & 130 & 52 \\
\hline Zambia & 127 & 55 \\
\hline
\end{tabular}

the probability of death between birth and the age of 5 years and is usually expressed per 1,000 or 100,000 live births [18]. The results of this study align with those of another study conducted by the World Bank [19], in which the child mortality of Nepal was found to be 33 per 100,000 live births. Similar findings have also been well documented elsewhere in the literature $[19,20]$. Moreover, most of the African countries had higher rates of under-5 mortality than Asian and Western countries. Nonetheless, under- 5 mortality has gradually declined in these 52 countries [21,22]. It may therefore be reasonable assume that all of these countries have made considerable investments in child health policies, advanced medical interventions, and the establishment of rehabilitation facilities and services. Numerous studies have observed similar findings; from 1990 to 2015, the world has remarkably reduced under-5 mortality by two-thirds by following political commitments, combatting poverty and hunger, and implementing favorable policies and interventions regarding the environment, medical technology, and public health $[3,4,10,22]$. 
Table 3. Under-5 Mortality Rate per 100,000 Live Births for 19 Asian Countries $(N=19)$

\begin{tabular}{|c|c|c|}
\hline Country & $\begin{array}{c}\text { Death rate/ } \\
100,000 \text { live } \\
\text { births in } 1990\end{array}$ & $\begin{array}{c}\text { Death rate/ } \\
100,000 \text { live } \\
\text { births in } 2015\end{array}$ \\
\hline Armenia & 93 & 45 \\
\hline Bangladesh & 62 & 35 \\
\hline Bhutan & 108 & 35 \\
\hline China & 64 & 23 \\
\hline India & 104 & 38 \\
\hline Indonesia & 83 & 27 \\
\hline Iran & 82 & 35 \\
\hline Japan & 39 & 12 \\
\hline Malaysia & 58 & 30 \\
\hline Mongolia & 98 & 25 \\
\hline Myanmar & 116 & 37 \\
\hline Nepal & 103 & 33 \\
\hline North Korea & 41 & 28 \\
\hline Papua New Guinea & 80 & 35 \\
\hline Philippines & 82 & 28 \\
\hline Sri-Lanka & 55 & 26 \\
\hline Thailand & 59 & 18 \\
\hline Uzbekistan & 118 & 34 \\
\hline Vietnam & 80 & 29 \\
\hline
\end{tabular}

Table 4. Under-5 Mortality Rate per 100,000 Live Births for 12 Western Countries $(N=12)$

\begin{tabular}{lcc}
\hline Country & $\begin{array}{c}\text { Death rate/ } \\
100,000 \text { live } \\
\text { births in } 1990\end{array}$ & $\begin{array}{c}\text { Death rate/ } \\
\text { 100,00 live births } \\
\text { in } 2015\end{array}$ \\
\hline Albania & 126 & 31 \\
Argentina & 44 & 18 \\
Brazil & 62 & 24 \\
Bulgaria & 47 & 21 \\
Columbia & 64 & 26 \\
Fiji & 64 & 50 \\
Honduras & 90 & 32 \\
Mexico & 86 & 22 \\
Paraguay & 71 & 26 \\
Peru & 92 & 33 \\
Uruguay & 60 & 25 \\
Venezuela & 60 & 23 \\
\hline
\end{tabular}

Throughout the world, 15,000 children under the age of 5 died every day in 2017 [4]. African countries are the most directly affected by this issue and account for a high proportion of under-5 child mortality [11], especially in eastern, central, and western Africa. A high burden of communicable disease, lack of strengthened healthcare facilities, poor hygiene and water supplies, severe droughts, and unstable government are possible explanations for child mortality $[20,23,24]$. Similar findings have been discussed in other studies [20,21], which also mentioned these issues regarding the ongoing burden of child mortality in this region, where significant improvements have yet to be made in child mortality. Therefore, millions of children in these regions face threats to their future due to the constraints of supply and demand regarding services and broader political, social, economic, and environmental determinants [21-24]. In contrast, Algeria, Morocco, and South Africa have achieved progressive reductions in child mortality in the last two decades $[25,26]$. This improvement may have been due to the breakdown of disparities and gender-discriminatory policies, improved socioeconomic status, good maternal and child health, and an emphasis on sanitation and hygiene programs [27]. Similar findings have been reported in other studies $[27,28]$, which found that Middle Eastern and some southern African countries have made remarkable progress in reducing child mortality since the 1960s $[26,27,29]$. This progressive decline in mortality is due to the expansion in the literacy rate, increases in living standards, widespread political stability, and control of HIV/AIDS, all of which have led to strong coverage and performance of the healthcare system [29].

Furthermore, of the South Asian countries (Bangladesh, Bhutan, India, Iran, Nepal, and Sri Lanka), India bore the highest burden of child mortality. In Southeast Asia (Indonesia, Myanmar, Malaysia, Philippines, Thailand, and Vietnam), Malaysia showed the highest child mortality rate, and a Western Asian country (Armenia) showed the highest child mortality rate. These persistently high rates of child mortality may be due to infections during birth, birth trauma, low birth weight, early marriage, and low rates of antenatal and postnatal care. Similar findings have been consistently reported in other studies $[10,29]$. Throughout the world, every day around 19,000 and 16,000 children under the age of 5 years died every day in 2011 and 2015, respectively [4,9]. Half of these deaths occur in South Asian (Afghanistan, India, and Pakistan) and sub-Saharan African countries [9], for reasons including poor health care facilities, conservative societies, war, and conflict $[10,30]$. In contrast, the under-5 mortality rate is somewhat lower and has been successfully reduced in East and West Asia, followed by Central and South Asia. This may be due to the good coverage of basic services in accordance with funda- 
mental human rights, including antenatal and postnatal care and immunization. Other studies have likewise found the most rapid declines in child mortality in East and West Asia between 1990 and 2015 [14,29]. During this period, low-cost interventions (e.g., oral rehydration service, immunization) and good maternal and child health care facilities have expanded, with appropriate legislation in these countries [14].

Moreover, in Western countries, significant progress has been made in reducing child mortality, with decreases more than three times higher than those in Africa and two times higher than those in Asia. This achievement has been made possible by effective interventions for infectious disease, political commitment, and appropriate investments in medical and nursing facilities and other applicable services, as has also been documented in other studies [22]. Western countries have made progress in expanding access to immunization and other preventive actions for disease control, good sanitation, and hygienic food and water supplies, leading to impressive progress in child mortality [10]. The impact of these economical interventions has proven the effectiveness of universal coverage of fundamental services, which prevented 5.6 million deaths of children under the age of 5 years worldwide in 2016 [10,23]. In this regard, there is a need to continue battling against child morbidity and mortality to achieve the goal of reducing under- 5 child mortality by two-thirds between the period of 1990 to 2015, in accordance with the Millennium Development Goals, and to 25 per 100,000 live births in all countries in alignment with the SDGs [10,29]. In this study, we used a simple mathematical method to estimate trends in under- 5 child mortality in 52 countries over time based on population data. Children from low- and middle-income countries still have a higher risk of death and are more vulnerable than those in high-income countries. However, the study focused only on 52 countries where there is low migration, and this method is not applicable to high-migration countries.

\section{CONCLUSION}

The study estimated under- 5 child mortality rates in 52 lowmigration countries using a simple method. The highest child mortality rates were found in Africa, followed by Asia and the West. The findings of this study indicate that more programs should be focused on child health and survival, especially in sub-Saharan Africa and even in some Asian countries.

\section{Conflict of interest}

No existing or potential conflict of interest relevant to this article was reported.

\section{Data availability}

Please contact the corresponding author for data availability.

\section{Acknowledgements}

The authors would like to thank the US Census Bureau of Statistics for providing the annual population data for children under 5 years of age.

\section{REFERENCES}

1. NICHD Early Child Care Research Network. Child-care structure $\rightarrow$ process $\rightarrow$ outcome: Direct and indirect effects of child-care quality on young children's development. Psychological Science. 2002;13(3):199-206. https://doi.org/10.1111/1467-9280.00438

2. Burchinal MR, Roberts JE, Nabors LA, Bryant DM. Quality of center child care and infant cognitive and language development. Child Development. 1996;67(2):606-620.

https://doi.org/10.2307/1131835

3. Duncan GJ, Brooks-Gunn J. Family poverty, welfare reform, and child development. Child Development. 2000;71(1):188-196. https://doi.org/10.2307/1132232

4. United Nations International Children's Fund. The state of the world's children 2016: A fair chance for every child [Internet]. New York, NY: United Nations for Children's Fund; 2016 [cited 2019 March 15]. Available from:

https://www.unicef.org/publications/files/UNICEF_SOWC_20 16.pdf

5. Chikhungu LC, Newell ML, Rollins N. Under-five mortality according to maternal survival: A systematic review and meta-analysis. Bulletin of the World Health Organization. 2017;95:281-287. https://doi.org/10.2471/BLT.15.157149

6. Wagstaff A, Bustreo F, Bryce J, Claeson M; Who-World Bank Child Health and Poverty Working Group. Child health: Reaching the poor. American Journal of Public Health. 2004;94(5):726-736. https://doi.org/10.2105/ajph.94.5.726

7. Currie J, Rossin-Slater M. Early-life origins of life-cycle well-being: Research and policy implications. Journal of Policy Analysis and Management. 2015;34(1):208-242.

https://doi.org/10.1002/pam.21805

8. You D, New JR, Wardlaw T, Inoue M, Mathers C, Boerma T, et al. Levels and trends in child mortality: Estimates developed by the UN Inter-agency Group for child mortality estimation report 2012 [Internet]. New York, NY: UNICEF; 2012 [cited 2019 January 19]. Available from:

https://www.who.int/maternal_child_adolescent/documents/ levels_trends_child_mortality_2012.pdf?ua=1

9. United Nations Children's Fund; World Health Organization; The World Bank; United Nations Population Division. Levels and 
trends in child mortality: Report 2012 [Internet]. New York, NY: United Nations Children's Fund; 2012 [cited 2019 January 29]. Available from:

https://www.who.int/maternal_child_adolescent/documents/ levels_trends_child_mortality_2012.pdf?ua=1

10. Black RE, Cousens S, Johnson HL, Lawn JE, Rudan I, Bassani DG, et al. Global, regional, and national causes of child mortality in 2008: A systematic analysis. Lancet. 2010;375(9730):1969-1987. https://doi.org/10.1016/S0140-6736(10)60549-1

11. Silva R. Child mortality estimation: Consistency of under-five mortality rate estimates using full birth histories and summary birth histories. PLOS Medicine. 2012;9(8):e1001296.

https://doi.org/10.1371/journal.pmed.1001296

12. Luy M. Estimating mortality differences in developed countries from survey information on maternal and paternal orphanhood. Demography. 2012;49(2):607-627. https://doi.org/10.1007/s13524-012-0101-4

13. Dwyer-Lindgren L, Kakungu F, Hangoma P, Ng M, Wang H, Flaxman AD, et al. Estimation of district-level under-5 mortality in Zambia using birth history data, 1980-2010. Spatial and Spatiotemporal Epidemiology. 2014;11:89-107. https://doi.org/10.1016/j.sste.2014.09.002

14. Alkema L, Chou D, Hogan D, Zhang S, Moller AB, Gemmill A, et al. Global, regional, and national levels and trends in maternal mortality between 1990 and 2015, with scenario-based projections to 2030: A systematic analysis by the UN Maternal Mortality Estimation Inter-Agency Group. Lancet. 2016;387(10017):462-474. https://doi.org/10.1016/S0140-6736(15)00838-7

15. United States Census Bureau. International Data Base [Internet]. Washington D.C: United States Census Bureau; 2015 [cited 2019 January 21]. Available from:

https://www.census.gov/data-tools/demo/idb/information Gateway.php

16. Gautam N, Ueranantasun A, Lim A. The models of age-specific mortality rates and their patterns from female total population counts. Journal of Population and Social Studies. 2018;26(3):235247. https://doi.org/10.25133/JPSSv26n3.017

17. United Nations. Population division: World population prospects 2019 [Internet]. New York, NY: United Nations; 2019 [cited 2019 January 15]. Available from: https://esa.un.org/unpd/wpp/dataquery/

18. World Health Organization. Background note on methodology for under-five mortality estimation [Internet]. New York, NY: World Health Organization; 2007 [cited 2018 December 22]. Available from: https://www.unicef.org/media/files/BACKGROUND_NOTE_ ON_METHODOLOGY_FOR_UNDER-FIVE_MORTALITY_ESTI MATION_web.pdf

19. The World Bank. Mortality rate, infant (per 1,000 live births)-India [Internet]. Washington D.C: The World Bank; 2019 [cited 2019 Feb 15]. Available from:

https://data.worldbank.org/indicator/SP.DYN.IMRT.IN?locations
$=\mathrm{IN}$

20. The World Bank. Disease and mortality in sub-Saharan Africa [Internet]. 2nd ed. Washington D.C: The World Bank; 2006 [cited 2018 December 22]. Available from:

https://www.ncbi.nlm.nih.gov/books/NBK2279/pdf/Bookshelf _NBK2279.pdf

21. United Nations Children's Fund; World Health Organization; The World Bank. United Nations Population Division. Mortality rate, infant, male (per 1,000 live births) [Internet]. Washington D.C: The World Bank; 2017 [cited 2018 December 29]. Available from: https://data.worldbank.org/indicator/SP.DYN.IMRT.MA.IN

22. Vakili R, Moghadam ZE, Khademi G, Vakili S, Saeidi M. Child mortality at different world regions: A comparison review. International Journal of Pediatrics. 2015;3(4.2):809-816.

23. UNICEF; WHO; World Bank Group; United Nations. Levels and trends in child mortality report 2018 [Internet]. New York, NY: UNICEF; 2018 [cited 2019 December 29]. Available from: https://www.unicef.org/publications/index_103264.html

24. Kandala NB, Mandungu TP, Mbela K, Nzita KP, Kalambayi BB, Kayembe KP, et al. Child mortality in the Democratic Republic of Congo: Cross-sectional evidence of the effect of geographic location and prolonged conflict from a national household survey. BMC Public Health. 2014;14:266. https://doi.org/10.1186/1471-2458-14-266

25. Becher H, Müller O, Dambach P, Gabrysch S, Niamba L, Sankoh O, et al. Decreasing child mortality, spatial clustering and decreasing disparity in North-Western Burkina Faso. Topical Medicine and International Health. 2016;21(4):546-555.

https://doi.org/10.1111/tmi.12673

26. World Health Organization. Morocco takes a stride forward for mothers and children [Internet]. Morocco: World Health Organization; 2014 [cited 2019 December 27]. Available from:

https://www.who.int/features/2014/morocco-maternal-health /en/\#: :text=Morocco\%20has\%20already\%20made\%20substant ial,bring\%20about\%20even\%20faster\%20progress

27. Wardlaw T, You D, Hug L, Amouzou A, Newby H. UNICEF Report: Enormous progress in child survival but greater focus on newborns urgently needed. Reproductive Health. 2014;11:82. https://doi.org/10.1186/1742-4755-11-82

28. Ahmad OB, Lopez AD, Inoue M. The decline in child mortality: A reappraisal. Bulletin of the World Health Organization. 2000; 78:1175-1191.

29. The United Nations Children's Fund. Under-five mortality [Internet]. New York, NY: The United Nations Children's Fund; 2020 [cited 2020 September 27]. Available from: https://data.unicef.org/topic/child-survival/under-five-mortality/

30. Rasooly MH, Govindasamy P, Aqil A, Rutstein S, Arnold F, Noormal B, et al. Success in reducing maternal and child mortality in Afghanistan. Global Public Health. 2014;9(Suppl 1):S29-S42. https://doi.org/10.1080/17441692.2013.827733 